\title{
AS CONTRIBUIÇÕES DO PROGRAMA INSTITUCIONAL DE BOLSAS DE INICIAÇÃO À DOCÊNCIA (PIBID) NA FORMAÇÃO DOCENTE DOS ALUNOS DE GEOGRAFIA DA UNIVERSIDADE FEDERAL DE PERNAMBUCO (UFPE)
}

\author{
Anderson Santos de Santana \\ Graduado em Geografia - Universidade Federal de Pernambuco \\ santosantana89@hotmail.com
}

Francisco Kennedy Silva dos Santos Prof. Dr. do Departamento de Ciências Geográficas da Universidade Federal de Pernambuco kennedyufpe@gmail.com

\section{Resumo}

Esta pesquisa teve como objetivo investigar as contribuições do PIBID da área de Geografia na melhoria da prática de ensino e da aprendizagem no contexto escolar do ensino médio com baixo desempenho em avaliações censitárias. Este propósito incidiu sobre as contribuições do PIBID da área de Geografia para a aprendizagem da docência por parte dos licenciandos e o incremento do ensino nas escolas de ensino médio pernambucano. Como procedimentos, utilizou-se da revisão de literatura e do levantamento documental para aprofundamento das categorias de investigação; aplicação de questionários aos sujeitos da pesquisa constituídos de questões abertas e fechadas; e realização de entrevistas semi-estruturadas. Essa investigação nos permitiu constatar que os objetivos do PIBID estão sendo contemplados no processo formativo dos licenciandos em geografia da UFPE. Ao analisar os dados coletados e interpretálos, pudemos perceber que, ao propor o incentivo a formação docente, valorização do magistério, integração entre ensino superior e educação básica, prática no ambiente profissional, participação efetiva dos professores do ensino médio e articulação entre teoria e prática, o programa busca proporcionar aos licenciandos uma formação fundamentada na reflexão e na problematização de situações reais relacionadas à atividade docente.

Palavras-chave: Formação de Professores, Ensino de Geografia, PIBID.

THE CONTRIBUTIONS OF THE TEACHING OF INSTITUTIONAL

\section{SCHOLARSHIPS PROGRAM STARTED (PIBID) IN TEACHER TRAINING OF STUDENTS OF GEOGRAPHY OF PERNAMBUCO FEDERAL UNIVERSITY} (UFPE)

\begin{abstract}
This research aimed to investigate the contributions of Geography Area PIBID in improving teaching practice and learning in the school context high school underperforming on census assessments. This purpose focused on the contributions of Geography Area PIBID for learning teaching by the licensees and the increase of education in Pernambuco middle schools. As
\end{abstract}


procedures, we used the literature review and documentary survey to deepen the research categories; questionnaires were applied to the research subjects made up of open and closed questions; and carrying out semi-structured interviews. This research allowed us to see that the PIBID objectives are being included in the training process of undergraduates in geography UFPE. By analyzing the collected data and interpret them, we realize that, in proposing the encouragement of teacher training, teaching appreciation, integration between higher education and basic education, practice in the workplace, effective participation of high school teachers and articulation between theory and practice, the program seeks to provide undergraduate training based on reflection and questioning of real situations related to teaching activity.

Keywords: Teacher Education, Geography Education, PIBID.

\section{Introdução}

Neste momento histórico de consolidação das prerrogativas propostas pela Lei de Diretrizes e Bases da Educação Nacional, Lei n.9394/96 e seus dispositivos complementares e da resolução $n^{\circ}$ 2, de 30 de janeiro de 2012 que define as Diretrizes Curriculares Nacionais para o Ensino Médio em seu Art. 13, alínea II e III, advoga a presença do trabalho como princípio educativo, para a compreensão do processo histórico de produção científica e tecnológica, desenvolvida e apropriada socialmente para a transformação das condições naturais da vida e a ampliação das capacidades, das potencialidades e dos sentidos humanos, enquanto que a pesquisa é concebida como princípio pedagógico, possibilitando que o estudante possa ser protagonista na investigação e na busca de respostas em um processo autônomo de (re)construção de conhecimentos. Estas proposições exigem da Universidade o estreitamento entre ensino e pesquisa na formação de professores para o trabalho docente, criando um grande desafio: formar o professor pesquisador da/na educação básica.

Surge no cenário educativo nacional uma diversidade de análises e reflexões sobre a formação continuada de professores. Evidencia-se esta realidade em face do conjunto de acervos bibliográficos em que são divulgadas novas bases conceituais apoiadas em pesquisas e reflexões de especialistas e pesquisadores na área. Em inúmeros seminários, foros e encontros acadêmicos discutem-se a sistematização e difusão das mais recentes reconceitualizações do trabalho docente e, ao mesmo tempo implementam-se experiências inovadoras na prática pedagógica relacionada à formação profissional do educador, à metodologia da interação que trata da construção, apropriação e difusão de conhecimentos (articulação entre ciência e cultura) e, propriamente, à pesquisa, concebida como princípio educativo (DEMO, 1991). 
As reflexões iniciais em torno da relação da teoria com a prática apontam para a complexidade da prática pedagógica, uma vez que nela se expressam múltiplos determinantes, ideias, valores e usos pedagógicos. Os próprios efeitos do ato educativo dependem da interação complexa de todos os aspectos e variáveis, que se entrecruzam nas situações de ensino, como a cultura organizacional, formação do docente, meios e condições físicas existentes.

Indubitavelmente, a primeira base intelectual de um profissional de ensino é o domínio de conteúdos relativos à prática que desenvolve. Mas, como expressa Sacristán (1998), não é um domínio indiscriminado, fruto da mera acumulação de conhecimentos, pesquisas e perspectivas diversas, e sim, um conjunto estruturado de conhecimentos e saberes, guardado seu significado educativo, social e histórico.

As implicações dessa temática podem ser vistas nos estudos de Philippe Perrenoud, Antônio Nóvoa e Keneth Zeichner, ainda que acompanhando análises voltadas para outras questões específicas, como as competências ou a identidade do professor Perrenoud (1993; 1999), Nóvoa, (1991; 1992), ou a questão do professor-pesquisador Zeichner, (1993; 1997; 1998).

Segundo Stenhouse (1975 apud LÜDKE, 2001, online), o professor deveria experimentar em cada sala de aula, tal como num laboratório, as melhores maneiras de atingir seus alunos no processo de ensino/aprendizagem.

As contribuições teóricas até então desenvolvidas, apontam para um conjunto de capacidades e habilidades adquiridas pelo professor, as quais o instrumentalizam a manejar a complexidade dos problemas por meio da investigação inteligente e criativa dos saberes adquiridos no exercício contínuo da docência.

Neste cenário insere-se o Programa Institucional de Bolsas de Iniciação à Docência (PIBID). O Programa foi criado pela Fundação Coordenação de Aperfeiçoamento do Ensino Superior (CAPES), com a finalidade de valorizar o magistério e apoiar estudantes de licenciatura plena, das instituições municipais públicas e comunitárias, sem fins econômicos, de educação superior (Lei $\mathrm{n}^{\circ} 11.502$, de 11 de julho de 2007). O Programa atende às diretrizes do Plano de Metas Compromisso Todos pela Educação (Decreto ${ }^{\circ}$ 6.094, de 24 de abril de 2007), aos princípios da Política Nacional de Formação de Profissionais do Magistério da Educação Básica (Decreto n 6.755, de 29 de janeiro de 2009 e Lei n ${ }^{\circ} 11.947$, de 16 de junho de 2009, no seu Art. 31) e de normas do MEC e atribuições legais da CAPES. 
Um dos objetivos do PIBID é a elevação da qualidade das ações acadêmicas voltadas à formação inicial de professores nos cursos de licenciatura das instituições de educação superior. Assim como a inserção dos licenciandos no cotidiano de escolas da rede pública de educação, o que promove a integração entre educação superior e educação básica. O Programa visa também proporcionar aos futuros professores participação em experiências metodológicas, tecnológicas e práticas docentes de caráter inovador e interdisciplinar e que busquem a superação de problemas identificados no processo de ensino-aprendizagem. Além de incentivar as escolas públicas de educação básica a tornarem-se protagonistas nos processos formativos dos estudantes das licenciaturas, mobilizando seus professores como co-formadores dos futuros professores.

O Programa oferece bolsas de iniciação à docência aos alunos de cursos presenciais que se dediquem ao estágio nas escolas públicas e que, quando graduados, se comprometam com o exercício do magistério na rede pública. $\mathrm{O}$ objetivo é antecipar o vínculo entre os futuros mestres e as salas de aula da rede pública. Com essa iniciativa, o PIBID faz uma articulação entre a educação superior (por meio das licenciaturas), a escola e os sistemas estaduais e municipais.

A intenção do Programa é unir as secretarias estaduais e municipais de educação e as universidades públicas, a favor da melhoria do ensino nas escolas públicas em que o Índice de Desenvolvimento da Educação Básica (IDEB) esteja abaixo da média nacional, de 4,4. Entre as propostas do PIBID está o incentivo à carreira do magistério nas áreas da educação básica com maior carência de professores com formação específica.

A Universidade Federal de Pernambuco (UFPE) através de seu projeto institucional e seguindo o que disciplina a Portaria 260/2010-CAPES atende atualmente 5 (cinco) escolas da rede pública de ensino nas áreas de Letras/Português, Musica, Teatro/Artes Cênicas, Artes/Plásticas e Visuais, Filosofia, Ciências Sociais/Sociologia, Geografia, Pedagogia, Matemática, Química, Biologia, Interdisciplinar/ (Biologia/Física/Química) e Física.

O PIBID da área de Geografia, campus Recife, contou no período de 2011-2013 com 15 bolsistas de Iniciação à Docência, sendo 5 por ano de subprojeto, que desenvolveram projetos nesta área de conhecimento na escola Estadual Senador Novaes Filho, espaço selecionado por excelência para o desenvolvimento desta investigação.

O projeto é movido pela seguinte questão: Qual a relação do PIBID Geografia na promoção da construção de um projeto de formação centrado nos dilemas da prática e suas 
interfaces para efetivação dos princípios pedagógicos da identidade, diversidade e autonomia, da interdisciplinaridade e da contextualização dos conceitos geográficos?

Diante desta questão, nos deparamos com uma realidade pedagógica diferente das décadas passadas, a globalização modificou a sociedade e a forma como as pessoas vivem, transformando a realidade econômica, cultural e política. Na educação surgiram novos paradigmas e novos tipos de aprendizagens, como as novas tecnologias, transformando a escola e mudando a prática de ensino do professor. O aluno, porém, se integrou facilmente com essas fontes de aprendizagem, pois essas tecnologias se popularizaram rapidamente e esse jovem facilmente se adapta a transformação acelerada da sociedade atual. O professor diante dessa perspectiva se viu atrasado, despreparado, pois o sistema educacional vem se transformando aceleradamente. No âmbito acadêmico vemos algumas dificuldades diante dessas transformações, por isso que atualmente tem se discutido sobre a qualidade da formação docente do futuro professor da educação básica da rede pública, pois as condições de ensino nessas escolas não garantem uma boa aprendizagem. Nos seus 63 anos de existência o curso de Licenciatura em Geografia da Universidade Federal de Pernambuco - UFPE, atualmente vem enfrentando alguns problemas na preparação do seu futuro professor, isso se deve pelo fato de que a formação docente do curso foi formada a partir de um modelo tecnicista como afirma Gallo e Rivero:

É pela orientação tecnicista que os professores são preparados para serem os grandes memorizadores de informações, compilados em livros técnicos ou didáticos, observados na integralidade de seus conteúdos, que também serão exigidos de seus alunos. (GALLO e RIVERO, 2004. pag.38).

Mesmo com as políticas publicas, como a Lei de Diretrizes e Bases - LDB, que trouxe mudanças importantes na formação de docentes no Brasil, o contexto histórico ainda é forte no curso de Geografia - UFPE. E há alguns problemas que devem ser enfrentados dentro do curso como a união entre teoria e prática, já que "essa separação resulta na construção de um corpus teórico hermético, incapaz de se colocar em relação, de forma dialética, com a prática concreta" (ROSA, 2006, pag. 112). É preciso integrar ensino e pesquisa, pois internamente os professores focam a pesquisa para a preparação do seu futuro pesquisador e técnico, desvalorizando o licenciando como pesquisador. É importante destacar que é com a pesquisa que esse futuro professor irá produzir novos conhecimentos e se preparar, como defende Gallo e Rivero: 
É por meio da pesquisa que o professor irá buscar novas metodologias que lhe possibilitem desenvolver um trabalho pedagógico, interdisciplinar, transdisciplinar, e não como compartimentos estanques. (GALLO e RIVERO, 2004. Pag.47).

Ainda se vê uma falta de integração entre as disciplinas especificas e pedagógicas, como suas práticas e métodos de ensino, o que mostra um desinteresse entre os docentes. Há uma resistência de união entre o curso, a escola e a inter-relação dos seus conhecimentos, contudo "o espaço da escola é um espaço de formação, não só dos alunos, mas também dos professores" (ROSA, 2006, pag.46). Vemos ainda no curso, a pouca preocupação da Geografia no ensino e a realidade do professor na educação básica. Diante disso, pensar numa formação de qualidade é um desafio, contudo os seus efeitos podem produzir profissionais competentes, embargado por uma teoria e práticas consistentes, preparados para atuarem na realidade educacional, como defende António Nóvoa:

A formação de professores pode desempenhar um papel importante na configuração de uma "nova" profissionalidade docente, estimulando a emergência de uma cultura profissional no seio do professorado e de uma cultura organizacional no seio das escolas. (NÓVOA, 1991).

Porém essa formação não se constrói de maneira rápida, pois o aluno antes de conseguir essa posição, ele precisa passar por um processo de constituição de sua identidade que deve iniciar a partir de sua entrada na academia, esse processo vai determinar e influenciar na qualificação de sua formação profissional, entretanto, o grande problema é a própria concepção da formação, existe hoje uma oposição entre a pesquisa e o ensino, uma aversão entre a teoria e a prática docente e uma desvalorização do magistério, essas dicotomias leva a uma fragilidade na formação docente como afirma Perrenoud:

Sem pretender que a formação acadêmica dos professores seja perfeita, reconheçamos, entretanto, que deixa menos a desejar que a formação didática e pedagógica. O desequilíbrio é maior no ensino secundário e otimiza-se no ensino superior, já que uma parte dos professores universitários assumem este papel sem nenhuma formação didática (PERRENOUD, 1999: 03).

Permitir que os alunos de licenciatura tenham uma experiência, observem e vivenciem o cotidiano da escola, dará a ele uma melhor formação, qualificando-o como um futuro profissional docente, diante disso, o Programa Institucional de Bolsa de Iniciação a Docência (PIBID) tem sido uma proposta do governo federal, junto com a UFPE, de oferecer uma mudança na formação inicial de professores, valorizando assim as licenciaturas e incentivando 
a docência, ao inserir os licenciandos previamente nas escolas sob a coordenação do professor universitário que tem o papel de coordenador da área, com a supervisão do professor da educação básica como função de professor supervisor, sendo este, contemplado pelo programa de ser um co-formador dos futuros docentes. Portanto um dos objetivos principais do PIBID é melhorar a formação de futuros professores para a Educação Básica como aprimorar a qualidade dessa educação, proporcionando a esses licenciandos participação em experiências metodológicas, tecnológicas e praticas docentes de caráter inovador e interdisciplinar e buscar a superação de problemas identificados no processo de ensino-aprendizagem. Além de incentivar as escolas publicas de educação básica a tornarem-se protagonistas nos processos formativos dos estudantes das licenciaturas, mobilizando seus professores como co-formadores dos futuros professores.

\section{Objetivo}

O estudo procurou-se investigar as contribuições do PIBID da área de Geografia na melhoria da prática de ensino e da aprendizagem no contexto escolar do ensino médio com baixo desempenho em avaliações censitárias. Este propósito incidiu sobre dois focos: de um lado, a execução do programa enquanto política voltada tanto para o fortalecimento da formação de docentes para a educação básica quanto para a melhoria da qualidade do ensino; de outro, as contribuições do PIBID da área de Geografia para a aprendizagem da docência por parte dos licenciandos e o incremento do ensino nas escolas de ensino médio pernambucano. Este propósito da investigação considera o fato deste programa ter como objetivo incentivar e fortalecer a formação de professores para a educação básica, estando, portanto, inserido no contexto da formação de professores no Brasil.

\section{Metodologia do Trabalho}

A proposta de pesquisa, aqui apresentada, configurou-se como uma pesquisa-formação. A participação nesse processo exige um mergulho no cenário de pesquisa para acompanhamento de todas as etapas de planejamento, execução e avaliação da área em estudo. Estas são ações exigentes do ponto de vista intelectual e emocional. Ações orientadas pela finalidade pedagógica da pesquisa como "prática mobilizadora de reflexão sobre o trabalho docente" (ANDRÉ, 1994, p. 294). 
Por se tratar de uma proposta de investigação e retroalimentação de saberes e práticas, optou-se por uma abordagem qualitativa. A pesquisa qualitativa rompe com os parâmetros epistemológicos do paradigma positivista, incorporando em seu fazer, o sujeito e sua subjetividade; valorizando a construção peculiar das práticas cotidianas, que passam a ser vistas, não por seus produtos palpáveis, objetivados, quantitativos, mas pelo processo significativo de sua construção, onde se incorpora as representações, os significados e o sentido existencial elaborado, (MINAYO, 1994). Para realização das etapas utilizou-se dos seguintes procedimentos: revisão de literatura e levantamento documental para aprofundamento das categorias de investigação; aplicação de questionários aos sujeitos da pesquisa constituídos de questões abertas e fechadas; e realização de entrevistas semi-estruturadas.

O projeto situa-se no campo do trabalho docente dos professores do ensino médio da Escola Estadual Senador Novaes Filho, em Recife, espaço por excelência das ações realizadas pelos licenciandos vinculados ao PIBID da área de Geografia da UFPE. A escolha da escola para participar da pesquisa apoiar-se-á, portanto, em uma intencionalidade, respaldada em Thiollent (1985), para o qual o princípio da intencionalidade é adequado no contexto da pesquisa qualitativa, onde todas as unidades não são consideradas equivalentes, ou de igual relevância.

Para análise e tratamento dos dados, optamos pela análise de conteúdos, conforme a proposta de Bardin (1995). A partir da orientação desse autor, na fase de organização dos dados, faremos a transcrição integral do material coletado, com o objetivo de se resgatar todo o conteúdo temático gerado. Através dessa metodologia buscamos identificar a significação dos dados coletados resultantes das entrevistas, questionários e das observações.

\section{Resultados e Discussão}

A pesquisa foi realizada no período entre Agosto de 2013 a Julho de 2014, tendo como referência o subprojeto PIBID-Geografia executado no período de vigência desta investigação. Participaram da pesquisa 5 bolsistas de Iniciação à Docência e 1 supervisor de Área. Dos 5 bolsistas investigados e do supervisor de área, 3 bolsistas já tinham participado de subprojeto da área de anos anteriores e o supervisor de todos os anos (2011 a 2013).

A unidade básica de ensino, lócus da pesquisa, foi a Escola Estadual Senador Novaes Filho. Há partir das analises dos questionários pode-se saber sobre o perfil e características de cada um dos sujeitos entrevistados. 
Os estudantes da Escola Estadual Senador Novaes Filho que participaram do subprojeto tinham uma ótima relação com os bolsistas do PIBID/Geografia, parceria que foi construída através das atividades proposta pelo projeto, como as oficinas de educação ambiental e Feiras de ciências/saberes. Nos encontros foram utilizados materiais, como: computador; projetor "data show"; maquetes; painéis; material reciclado. As atividades tinham como expoentes a apresentação de trabalhos por meio de oficinas.

Em algumas atividades, houve participação de professores de outras áreas de ensino da escola, o que estabelece um fio sistêmico para construção de um campo inter-transdisciplinar. Fato também que demonstra nestes professores um alto grau de curiosidade sobre o projeto PIBID e aceitação por parte deles, dessa intervenção de agentes externos no âmbito profissional. Atuaram também em conjunto com o PIBID/Geografia os bolsistas do subprojeto PIBID/Música na Feira de conhecimento da Escola Estadual Senador Novaes Filho (FECONF 2012 e 2013).

Um dos objetivos do subprojeto PIBID/Geografia era o de proporcionar aos alunos experiências fora do cenário escolar o qual eles já estavam habituados. Em dois anos os estudantes participaram em média de três excursões: Ao mirante do Centro de Filosofia e Ciências Humanas (CFCH/UFPE), à Estação Meteorológica do Recife e ao Lago do Cavouco (UFPE). Quando perguntados na pesquisa, sobre o que mudou com a chegada do PIBID/Geografia na escola, algumas das respostas foram: "mudou a temática das aulas usando projetores, filmes entre outros"; "As aulas ficaram mais interativas"; "Ficou mais divertida porque toda turma interagiu fazendo perguntas e tirando as duvidas". Percebemos que quando os alunos comentam sobre a mudança da temática, o mesmo refere-se à mudança da metodologia aplicada em sala, que mesmo sem saber, notou a diferença de como as aulas estão sendo ministradas, através de novas ferramentas de ensino como as músicas e filmes, como facilitadores do aprendizado, as aulas ficaram mais atrativas, provocando nos alunos uma maior interação entre eles e com os próprios professores.

Sobre o perfil e as experiências do professor supervisor do subprojeto PIBID/Geografia, destacamos em nossa investigação que a escolha de um profissional docente, especializado para o bom andamento do projeto, é de suma importância, pois, sua experiência e formação docente, são essenciais para a orientação dos bolsistas em suas atividades. O Supervisor escolhido pela coordenação do subprojeto teve sua formação em Licenciatura em Geografia na Universidade Católica de Pernambuco em 1991 e em 1996 formou-se Bacharel em Geografia pela 
Universidade Federal de Pernambuco. Tem especialização em Educação Ambiental e também possui Especialização em Ensino de Geografia. Obteve o titulo de Mestrado em Geografia em 2005. Atua como professor na rede estadual há mais de 20 anos, atualmente é professor efetivo na Escola Estadual Senador Novaes Filho, onde leciona as disciplina de Geografia e Artes. O supervisor do PIBID/Geografia além de acompanhar a assiduidade e andamento do projeto na escola, atuou junto com os bolsistas em atividades, como: Palestras; Visitas de estudos (Campo) e feiras de conhecimentos (FECONF).

Sobre os avanços no desenvolvimento dos alunos que participaram no subprojeto, o supervisor notou que eles estão mais estimulados e participativos nas aulas discursivas, "a chegada do PIBID/Geografia elevou o conhecimento cultural, filosófico e questionador dos alunos, as propostas trazidas pelo subprojeto a escola, proporcionaram uma nova tendência a educação, inovadora, uma ferramenta excelente para a motivação do aprendizado dos educandos". O supervisor ressalta ainda da necessidade de ampliação nos números de bolsistas para alcançar mais alunos da escola e implantar o subprojeto em outras unidades de ensino da rede pública.

Com a chegada do subprojeto PIBID/Geografia na escola, os professores acabam aprimorando os seus conhecimentos, através das vivencias trazidas pelos Pibidianos, os professores trocam as suas experiências, promovendo uma interação entre os jovens iniciantes, valorizando ainda mais o ensino da Geografia na escola, no entanto, em relação à eficácia dos métodos de ensino aplicados pelos bolsistas, o supervisor considerou: "São eficazes na maioria das vezes, porém, por falta de experiências/vivências em sala de aula, em algumas situações os bolsistas precisavam ainda de amadurecimento no manejo das aulas". Observa-se aqui a importância da participação do corpo docente da escola, na troca de saberes e vivências com os bolsistas. O subprojeto do PIBID/Geografia é concebido, portanto, para os bolsistas e supervisor, como um grande laboratório de ensino, contribuindo para sua formação enquanto professor de Geografia.

Em relação ao nível de troca de experiência entre os bolsistas PIBID/Geografia com os alunos da escola, os bolsistas consideraram como "boa", mesmo diante de algumas dificuldades que surgiram no inicio da implantação do subprojeto: "sempre surge impasse em se estabelecer contato, mas, com a convivência e o desenrolar das atividades, os problemas foram diminuídos". 
Na perspectiva dos bolsistas, existe um avanço no desenvolvimento dos alunos com a chegada do PIBID, ampliando a consciência socioambiental deles, pois, grande parte dos alunos viam o ensino da Geografia como mero disciplinamento escolar, não tinham desenvolvido a capacidade de entender o espaço, além de suas vivencias locais. Com o subprojeto PIBID/Geografia, surgiram indagações e questionamentos em relação as temáticas trabalhadas, proporcionando um maior senso crítico dos alunos.

Em relação à chegada do PIBID na escola, os bolsistas PIBID, entretanto, não consideraram satisfatório o envolvimento da gestão da unidade escolar, os bolsistas afirmaram que recebiam o mínimo de atenção por parte da gestão, apesar da atuação do supervisor. O supervisor poderia servir de interlocutor entre os alunos com a gestão, para desenvolver em conjuntos atividades onde mais alunos tivessem oportunidade de participar e promover interações com professores de outras disciplinas e até com outras escolas da rede, nesse contexto, o apoio da gestão da escola seria essencial.

Sobre o desenvolvimento do subprojeto PIBID/Geografia e seus desafios, foram destacados pelos bolsistas diversos pontos que devem ser melhorados no subprojeto do PIBID, como maior relação e atuação do supervisor do projeto; maior suporte financeiro para a realização das atividades e aumentar o numero de bolsistas. Segundo os bolsistas, foram encontrados muitos problemas, como: falta de estrutura; comunicação; apoio financeiro para a realização das atividades: "Procuramos mesmo com essas dificuldades, encontrar soluções, organizávamos precariamente nossas reuniões, utilizando espaços diversos e arcávamos com as despesas das atividades realizadas". As excursões os bolsistas consideraram: "bem proveitosas, do ponto de vista educacional, conteúdo trabalhado de forma simples, porém, precisa e bem diversificada. Há ressalvas apenas quanto o comportamento dos docentes". Algumas atividades elaboradas pelos bolsistas foram vetadas pela coordenação do subprojeto, como: excursões didáticas, alegando falta de recursos financeiros. Os bolsistas atuaram também na elaboração do plano de atividades, com sugestões de temáticas e formas de abordagens aos alunos.

\section{Conclusões}

O Pibid é um programa que vem com a proposta de melhorar a formação do professor nas universidades publicas no Brasil, construindo e fazendo um vinculo nos dois níveis de ensino, cabe aos bolsistas e professores aplicarem as propostas que o programa coloca, que é 
de fazer uma formação de qualidade e responsabilidade, pois formar o futuro educador exige capacidades e compromissos, como afirma António Nóvoa:

\begin{abstract}
A formação de professores deve ser concebida como uma das componentes da mudança, em conexão estreita com outros sectores e áreas de intervenção, e não como uma espécie de condição prévia da mudança. A formação não se faz antes da mudança, faz-se durante, produz-se nesse esforço de inovação e de procura dos melhores percursos para a transformação da escola. É esta perspectiva ecológica de mudança interactiva dos profissionais e dos contextos que dá um novo sentido às práticas de formação de professores centradas nas escolas. (NÓVOA, 1991).
\end{abstract}

A Geografia no Ensino Básico procura discutir o papel e a importância do conhecimento geográfico para a formação desses jovens educadores, participando do processo de construção dos fundamentos conceituais e instrumentais para compreensão e representação da vida e do mundo, através do estudo da realidade (CASTROGIOVANNI, KAERCHER, REGO, 2007). Antes disso, esses Pibidianos, precisam ser capacitados, produzir, adequar e utilizar os mais variados recursos multissensoriais que auxiliem na compreensão dos fenômenos geográficos, que possibilitará ao graduando sair da universidade com aptidão para utilizar recursos e as novas Tecnologias de Informação e Comunicação vinculadas a sua área de conhecimento.

Essa investigação nos permitiu constatar que os objetivos do PIBID estão sendo contemplados no processo formativo dos licenciandos em geografia da UFPE. Ao analisar as falas dos bolsistas e interpretá-las, classificando-as de acordo com nossa interpretação dos objetivos do programa, nossas categorias de análise, pudemos perceber que, ao propor o incentivo a formação docente, valorização do magistério, integração entre ensino superior e educação básica, prática no ambiente profissional, participação efetiva dos professores do ensino médio e articulação entre teoria e prática, o programa busca proporcionar aos licenciandos uma formação fundamentada na reflexão e na problematização de situações reais relacionadas à atividade docente.

Nos depoimentos, observamos que as relações estabelecidas no programa entre bolsistas, coordenadores e supervisores colaboram para que o licenciando tenha contato com as pesquisas desenvolvidas na área de ensino de geografia, com as experiências no ambiente escolar, possibilitando que este, já nos primeiros anos da licenciatura, comece a moldar sua identidade docente, fundamentando-se na percepção de que a profissão se constitui num ambiente complexo e singular. 
Nessa perspectiva, o PIBID/Geografia procura manter um ambiente que promova reflexões e discussões acerca de temas relacionados à construção do conhecimento geográfico, visto de uma perspectiva pedagógica, destacando a experimentação e a contextualização como ferramentas importantes no processo de ensino e aprendizagem da disciplina de Geografia, buscando, assim, melhorar a formação inicial dos professores e possibilitando um ensino de geografia de qualidade na educação básica.

Dessa forma, nossa investigação nos permitiu evidenciar que todas as ações desenvolvidas no subprojeto e orientadas pelo coordenador de área são propostas na intenção de alcançar os objetivos gerais do PIBID, determinados pelo Ministério da Educação.

\section{Referências}

ANDRÉ, M.E.D.A. Etnografia na prática escolar. Campinas: Papirus, 1994.

BARDIN, L. Análise do conteúdo. Tradução de L.A. Antero e A. Pinheiro. Lisboa: Edições 70, 1995.

BRASIL. Lei n. 9.394 de 20 de dezembro de 1996. Lei de Diretrizes e Bases da Educação Nacional. DOU de 23 de dezembro de 1996.

Lei $n^{\circ} 11.502$, de 11 de julho de 2007 que modifica as competências e a estrutura organizacional da fundação Coordenação de Aperfeiçoamento de Pessoal de Nível Superior CAPES.

Decreto n ${ }^{\circ} \mathbf{6 . 0 9 4}$, de 24 de abril de 2007 .

Decreto $\mathbf{n}^{\mathbf{0}} \mathbf{6 . 7 5 5}$, de 29 de janeiro de 2009, e Lei $\mathrm{n}^{\circ} 11.947$, de 16 de junho de 2009, no seu Art. 31.

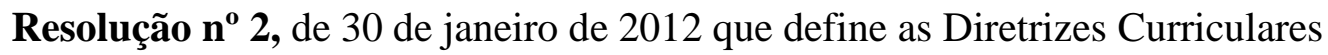
Nacionais para o Ensino Médio.

CASTROGIOVANNI, A. C.; KAERCHER, Nestor André; REGO, N. (Orgs.). Geografia práticas pedagógicas para o ensino médio. 1. ed. Porto Alegre: Artmed, 2007. v.1. 152p.

DEMO, Pedro. Pesquisa - Princípio científico e educativo. São Paulo: Cortez, 1991.

GALLO, Silvio; RIVERO, Cléia Maria L. A formação de Professores na Sociedade do Conhecimento. EDUSC, 2004

IBIAPINA, Ivana Maria Lopes de Melo. Pesquisa colaborativa - investigação, formação e produção de conhecimentos. Brasília: Ed. Liber, 2008. 
LÜDKE, Menga. O professor, seu saber e sua pesquisa. Educação e Sociedade. v. 22, n.74, Campinas, Abr. 2001. Acesso em mar. 2013. DOI: http://dx.doi.org/10.1590/S010173302001000100006

MINAYO, M.C.S. (Org.) Pesquisa Social: teoria, método e criatividade. Petrópolis, RJ: Vozes, 1994.

NÓVOA, António. Profissão professor. Porto: Porto Editora, 1991. .Vidas de professores. Porto: Porto Editora, 1992.

PERRENOUD, Philippe. Práticas pedagógicas, profissão docente e formação: perspectivas sociológicas. Lisboa: Publicações Dom Quixote, Instituto de Inovação Educacional, 1993.

Dez novas competências para ensinar. Porto Alegre: Artes Médicas, 1999.

ROSA, Dalva E. Gonçalves. Formação de professores: concepções e práticas em Geografia. Goiânia: E.V. 2006.

SACRISTÁN, J. G; GÓMEZ, A. I. Pérez. Compreender e transformar o ensino. Porto Alegre: Artmed, 1998.

STENHOUSE, L. An introduction to curriculum research and development. Londres: Heinemann, 1975.

THIOLLENT, Michel. Metodologia da pesquisa-ação. São Paulo: Cortez, 1985.

ZEICHNER, K. Para além da divisão entre professor-pesquisador e pesquisador acadêmico. In: GERALDI, FIORENTINI \& PEREIRA. Cartografias do trabalho docente. Campinas: Mercado das Letras/ALB, 1998, p.

207-236.

Action research as a professional development in one urban school district. Annual Meeting of the American Educational Research Association, Chicago, IL, março, 1997.

A formação reflexiva de professores: Ideias e práticas. Lisboa: Educa, 1993. 